\title{
Commentary: Better prediction, better execution, better management
}

\author{
Daniel J. P. Burns, MD, MPhil
}

\author{
From the Department of Thoracic and Cardiovascular Surgery, Cleveland Clinic Foundation, Cleveland, Ohio. \\ Disclosures: Author has nothing to disclose with regard to commercial support. \\ Received for publication July 24, 2019; accepted for publication July 25, 2019; available ahead of print Aug 22, \\ 2019 \\ Address for reprints: Daniel J. P. Burns, MD, MPhil, Cleveland Clinic, 9500 Euclid Ave, J4-133, Cleveland, OH \\ 44195 (E-mail: burnsd@ccf.org). \\ J Thorac Cardiovasc Surg 2020;160:130-1 \\ $0022-5223 / \$ 36.00$ \\ Copyright (c) 2019 by The American Association for Thoracic Surgery \\ https://doi.org/10.1016/j.jtcvs.2019.07.078
}

Coronary artery bypass grafting (CABG) has been the mainstay of adult cardiac surgery for decades. Throughout its history, debates have waxed and waned regarding the optimal grafting strategy. Despite the known advantages of arterial grafts in CABG, the saphenous vein graft remains the workhorse conduit. The question remains, which is the best strategy? The major drawback of saphenous vein grafts is their decreased longevity relative to arterial grafts. ${ }^{1,2}$ Increasing our ability to understand which grafts will and will not fail is certainly an important task.

In their article in this issue of the Journal, Antonopoulos and colleagues ${ }^{3}$ have undertaken 2 laudable goals. The first component involves a literature-based meta-analysis to describe the reported risk of early saphenous vein graft failure (within 1 postoperative year). This analysis has shown an $11 \%$ risk of early graft failure. Somewhat surprisingly, this risk improves only to $7 \%$ when focusing on studies published after 2010. At first glance, this seems reasonable, until one reflects on the last few months of one's practice and starts counting $\mathrm{CABG}$ procedures performed. This certainly reveals a window of opportunity for improvement. If we focus here, we may be able to decrease early saphenous graft failure.

The second component of this article focuses on exactly this goal. By increasing our ability to predict which saphenous vein grafts will fail, we may ultimately improve our management of these patients. By analyzing individual participant data, Antonopoulos and colleagues ${ }^{3}$ have developed a novel prediction model for early saphenous vein graft occlusion. Twelve risk variables were ultimately included in the model. Generally, these were not surprising, although endoscopic harvest was found to be associated with a reduced risk of graft occlusion. Once the prediction model was derived, it performed reasonably in the derivation and validation cohorts, with calculated C-statistics of 0.744 and 0.734 respectively. Once the scoring metric was of assessed patients.

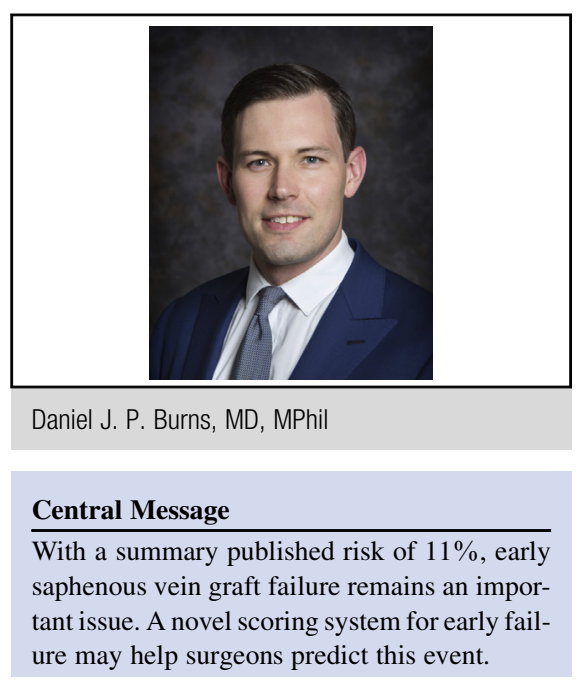

See Article page 116.

developed, it compared favorably with the original model, with a C-statistic of 0.70 , and correctly classified $83.7 \%$

We must interpret these results within a framework of important limitations. The meta-analysis and the prediction model account neither for the quality of the harvested conduit or of the target vessel nor for the degree of upstream stenosis. Differences in, and completeness of, angiographic follow-up may have led to the missed detection of important graft failures. It is also possible that unchecked interactions or residual confounding have influenced the results. Finally, it is important to look at the reported measures of model discrimination. A C-statistic of 0.70 is at the lower limit of what would be considered a "good" model.

Despite these limitations, this is an important study. There are clear implications for our field here. Is patient A a good candidate to receive a saphenous graft? Should we favor multiple or even total arterial revascularization? Should we place this patient on dual antiplatelet therapy afterward? Will it be important to be extra aggressive in medical therapy of comorbid illness? All these questions could be influenced by such a scoring metric. Although further careful study is certainly required, this should be considered an incremental but important step forward. 


\section{References}

1. Sabik JF III, Lytle BW, Blackstone EH, Houghtaling PL, Cosgrove DM. Comparison of saphenous vein and internal thoracic artery graft patency by coronary system. Ann Thorac Surg. 2005;79: 544-51.

2. Deb S, Cohen EA, Singh SK, Une D, Laupacis A, Fremes SE, RAPS Investigators. Radial artery and saphenous vein patency more than 5 years after coronary artery

bypass surgery: results from RAPS (radial artery patency study). J Am Coll Cardiol. 2012;60:28-35.

3. Antonopoulos AS, Odutayo A, Oikonomou EK, Trivella M, Petrou M, Collins GS, et al; SAFINOUS-CABG (SAphenous vein graft Fallure-AN OUtcomes Study in Coronary Artery Bypass Grafting) group. Development of a risk score for early saphenous vein graft failure: an individual patient data meta-analysis. J Thorac Cardiovasc Surg. 2020;160:116-27.e4. 